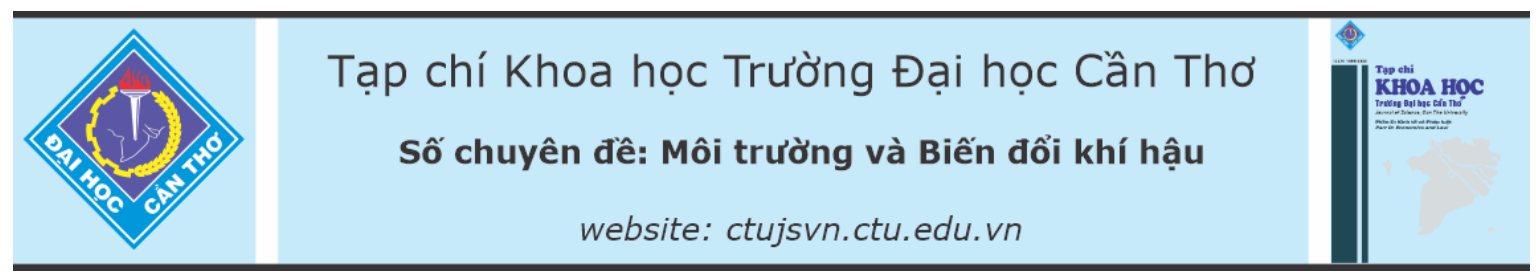

DOI:10.22144/ctu.jsi.2021.049

\title{
PHÂN TÍCH THỊ HIẾU NGƯờI TIÊU DÙNG ĐỐI VỚI SẢN PHẨM CẢI THẢO NHÃN HIỆU SINH THÁI: TRƯờnG HỘP NGHIÊN CÚU TẠI THÀNH PHỐ CẦN THO
}

\author{
Trần Trung Tín ${ }^{1}$, Huỳnh Việt Khải $i^{*}$, Trần Thị Thu Duyên ${ }^{2}$ và Nguyễn Thị Hồng Ngọc ${ }^{3}$ \\ ${ }^{1}$ Hoc viên cao họ Khoa Kinh tế, Truờng Đại học Cần Tho \\ ${ }^{2}$ Khoa Kinh tế, Trường Đại học Cần Tho \\ ${ }^{3}$ Sinh viên Khoa Kinh tế, Trường Đại học Cần Tho \\ *Nguoòi chịu trách nhiệm về bài viết: Huỳnh Việt Khải (email: hvkhai@ctu.edu.vn)
}

\section{Thông tin chung:}

Ngày nhận bài: $12 / 04 / 2021$

Ngày nhận bài sủa: 14/10/2021

Ngày duyệt đăng: 15/11/2021

\section{Title:}

Analysis of consumer preference for chinese cabbage with ecolabel: A case study in Can Tho city

\section{Tù khóa:}

Giá sã̃n lòng trả (WTP), mô hình lựa chọn, nhãn hiệu sinh thái, thưcc nghiệm lựa chọn

\section{Keywords:}

Willingness to pay (WTP), choice modeling, eco-label, choice experiment

\section{GIỚI THIỆU}

Trong năm 2018, Việt Nam có diện tích gieo trồng cây rau khá lớn khoảng 18.756 ha (tăng $8,6 \%$ so với cùng kỳ 2017), năng suất bình quân ước đạt khoảng 28,05 tấn/ha với tổng sản lượng ước đạt 526.106 tấn (Sở Nông nghiệp và Phát triển nông thôn thành phố Hồ Chí Minh, 2018). Tuy việc tăng sản lượng rau màu ở nước ta là một điều tốt nhưng, bên cạnh đó nó còn có mối lo ngại về tình trạng vệ sinh an toàn thực phẩm. Để đáp ứng đủ nhu cầu đa dạng về thực phẩm cho con người, kỹ thuật canh tác cũng là một yếu tố hết sức quan trọng. Vì vậy, người nông dân không ngừng nâng cao hiệu quả kỹ thuật, kết hợp sử dụng phân bón nhiều và sử dụng lượng thuốc bảo vệ thực vật quá mức cho phép, dẫn đến thực phẩm bẩn tràn lan trên thị trường hiện nay. Việt Nam đang sử dụng thuốc bảo vệ thực vật 100.000 tấn/năm (Phong Nguyễn, 2020). Sự lạm dụng thuốc bảo vệ thực vật gây độc hại cho chính người sản xuất, cộng đồng và hơn 90 triệu người dân Việt Nam lại đang phải vật lộn với cuộc chiến "rau, quả bẩn" để có được bữa ăn sạch hàng ngày cho chính gia đình mình. Vì thế, rau quả sạch và an toàn thật sự là một nhu cầu cấp thiết cho người tiêu dùng. Việc lựa chọn giữa rau sạch đạt chứng nhận an toàn hay rau hữu cơ với thông tin nhãn mác, thương hiệu đầy đủ và giá cả như thế nào là một vấn đề rất quan trọng. 
Hiện nay, các dự án sản xuất rau an toàn, rau hữu cơ không ngừng được đẩy mạnh và đã có rất nhiều nghiên cứu được thực hiện với mục tiêu phát triển chuỗi cung ứng rau sạch. Tuy nhiên, đa phần các nghiên cứu này chỉ tiếp cận ở gốc độ người sản xuất. Trong khi đó, để phát triển thị trường rau sạch một cách bền vững, có hiệu quả thì việc có góc nhìn chính xác và khách quan xem người tiêu dùng nhận thức thế nào về rau sạch, các yếu tố nào tác động tới hành vi của người tiêu dùng và mức sẵn lòng chi trả của họ cho việc ưu tiên lựa chọn rau sạch so với rau thông thường hiện có trên thị trường là cần thiết. Một nghiên cứu của Nguyễn Văn Thuận và Võ Thành Danh (2011) cho thấy rằng đa phần người sử dụng rau an toàn (RAT) ở thành phố Cần Thơ có trình độ học vấn và thu nhập khá cao. Điều này cho thấy thị trường RAT nằm trong phân khúc thị trường thu nhập cao. Kết quả khảo sát cho thấy có $67 \%$ số người được hỏi cho rằng họ đã mua RAT từ hơn một năm, và $33 \%$ số người được hỏi chỉ mua RAT ít hơn một năm. Điều này cho thấy xu hướng tiêu dùng RAT đang hình thành và có triển vọng nhiều trong thời gian tới khi nhận thức của người tiêu dùng thay đổi theo hướng tích cực trong hành vi tiêu dùng của mình. Đặc biệt, kết quả khảo sát về ý thức tiêu dùng RAT cho thấy có $100 \%$ người được hỏi nhận thức việc sử dụng RAT là có lợi cho sức khỏe. Tuy nhiên, vẫn còn một tỷ lệ cao $(45 \%)$ người tiêu dùng chưa hiểu biết một cách đầy đủ về tiêu chuẩn RAT.

Khai (2017) sử dụng phương pháp định giá ngẫu nhiên $(\mathrm{CVM})$ để phân tích mức độ sẵn sàng chi trả của người tiêu dùng đối với rau hữu cơ ở Đồng bằng sông Cửu Long (ĐBSCL). Người tiêu dùng quan tâm đến sức khỏe, an toàn thực phẩm có xu hướng tiêu dùng nhiều hơn và những người có thu nhập và trình độ học vấn cao cũng chấp nhận mua rau hữu cơ với giá cao hơn rau thông thường. Ngoài ra, người tiêu dùng ở ĐBSCL sẵn sàng trả mức giá cao hơn trung bình là $59 \%$ cho rau hữu cơ so với loại rau thông thường. Tương tự, Khai et al. (2020) cũng sử dụng phương pháp CVM để phân tích nhu cầu của người tiêu dùng đối với loại thịt lợn an toàn tại ĐBSCL cho thấy đa số người tiêu dùng (khoảng 64\%) sẵn sàng trả giá cao hơn gần gấp đôi so với giá thị lợn thông thường. Đồng thời, nghiên cứu chỉ ra thu nhập, tỷ lệ người già và trẻ em trong gia đình, kiến thức về sản phẩm an toàn và số thành viên trong gia đình có ảnh hưởng đến giá sẵn lòng trả (WTP) của người tiêu dùng sản phẩm an toàn.

Với mục tiêu cung cấp thêm bức tranh về hành vi của người tiêu dùng đối với sản phẩm RAT, bài viết này tập trung nghiên cứu về thị hiếu của người tiêu dùng đối với sản phẩm rau sạch với thương hiệu đảm bảo an toàn, cụ thể trong bài viết này là thị hiếu về cải thảo nhãn hiệu sinh thái của người tiêu dùng, trường hợp nghiên cứu tại thành phố Cần Thơ. Nghiên cứu có thể cung cấp cái nhìn rõ ràng hơn về vấn đề tiêu dùng thực phẩm xanh hiện nay với mục đích đánh giá thực trạng sử dụng và nhu cầu đối với loại rau có nhãn hiệu sinh thái; từ đó có cơ sở đề ra các kiến nghị và hàm ý chính sách nhằm đảm bảo được lợi ích mà người tiêu dùng được nhận gắn với việc phát triển một nền nông nghiệp bền vững.

\section{PHƯONG PHÁP NGHIÊN CÚU}

\subsection{Phương pháp thực nghiệm lựa chọn}

Phương pháp thực nghiệm lựa chọn (CE Choice Experiment) được sử dụng trong bài viết để ước lượng nhu cầu của người tiêu dùng đối với sản phẩm cải thảo nhãn hiệu sinh thái. Phương pháp này thuộc nhóm phương pháp phát biểu sở thích (Stated Preference). Trong $\mathrm{CE}$, người trả lời được trình bày với giả thuyết và yêu cầu lựa chọn thay thế ưa thích của họ trong một số lựa chọn thay thế trong một bộ lựa chọn (Hanley et al., 2001). CE có lợi thế hơn so với các phương pháp phát biểu sở thích khác như phương pháp đánh giá ngẫu nhiên (CVM Contingen Valuation Method) là có thể thu thập bộ dữ liệu phong phú hơn, giảm sai lệch trong thu thập số liệu, có tiềm năng chuyển đổi lợi ích, và có tính linh hoạt (Bennett \& Adamowicz, 2001).

Tương tự như các phương pháp phát biểu sở thích khác, $\mathrm{CE}$ cũng dựa vào và phù hợp với lý thuyết thỏa dụng ngẫu nhiên (Random Utility Theory) của Lancaster (1966) (Adamowicz et al., 1998; Louviere et al., 2000). Lý thuyết độ thỏa dụng ngẫu nhiên cho rằng độ thỏa dụng của cá nhân người tiêu dùng bao gồm hai phần: phần có thể quan sát được và phần không thể quan sát được. Phần có thể quan sát và đo lường được dựa trên sự đánh giá của người tiêu dùng đối với các đặc tính của sản phẩm và phần không thể quan sát được có tính ngẫu nhiên và tùy thuộc vào sở thích của cá nhân người đó. Ta ký hiệu phần có thể quan sát được là $V$ và phần không thể quan sát được là $e$. Hàm thỏa dụng $\left(U_{i j}\right)$ của một cá nhân $i$ khi tiêu dùng sản phẩm $j$ là:

$$
U_{i j}=V_{i j}+e_{i j}=V\left(Z_{i j}, S_{i}\right)+e
$$

Trong đó, giá trị $V_{i j}$ là vec-tơ mức độ các đặc tính $Z$ (phẩm chất) của sản phẩm $j$ cùng với các đặc điểm $S$ về kinh tế, xã hội, và thái độ của đáp viên $i$.

Với tập lựa chọn gồm nhiều sản phẩm khác nhau với các thuộc tính khác nhau, người tiêu dùng chọn sản phẩm nào mang đến độ thỏa dụng cao nhất cho họ. Xác suất để cá nhân $i$ chọn sản phẩm $j$ trong gói 
lựa chọn $C$ thay vì bất kỳ sản phẩm $m$ khác nào tương ứng với xác suất để $U_{i j}>U_{i m}$. Cụ thể xác suất để chọn $j$ của cá nhân $i\left(P_{i j}\right)$ là:

$$
\begin{aligned}
P_{i j} & =P\left(U_{i j}>U_{i m}\right) \\
& =P\left(V_{i j}+e_{i j}>V_{i m}+e_{i m}\right) ; \forall m \in C
\end{aligned}
$$

Giả định rằng thành phần ngẫu nhiên $e_{i j}$ theo dạng phân phối đồng nhất và độc lập (IID Independent and Identically Distributed) với quy luật phân phối Gumbell hoặc Weibull, xác suất mà lựa chọn $m$ sẽ được lựa chọn được ước tính với mô hình Logit đa lựa chọn (MNL - Multinomial Logit Model), mô hình được trình bày như sau:

$$
P_{i j}=\frac{\exp \left(V_{i j}\right)}{\sum_{m \in C} \exp \left(V_{i m}\right)}
$$

Phương trình tuyến tính về độ thỏa dụng cho sự lựa chọn sản phẩm thứ $j$ được viết như sau (Khai \& Yabe, 2014):

$$
\begin{gathered}
V_{i j}=A S C+\beta_{1} Z_{1}+\beta_{2} Z_{2}+\beta_{3} Z_{3}+\cdots+ \\
\beta_{k} Z_{k}+\lambda_{1}\left(A S C * S_{1}\right)+\cdots+\lambda_{p}\left(A S C * S_{p}\right)
\end{gathered}
$$

Trong đó, $A S C$ là hằng số cụ thể thay thế của mô hình MNL, và là duy nhất cho mỗi phương án được xem xét trong các lựa chọn; $A S C$ nắm bắt các hiệu ứng trung bình trên hữu dụng của bất kỳ yếu tố nào không có trong $V_{i} \cdot \beta_{k}$ là hệ số ước lượng thể hiện độ thỏa dụng biên của người tiêu dùng đối với đặc tính $k$ của sản phẩm, $k$ là số lượng các biến thuộc tính. $\lambda_{p}$ là hệ số ước lượng của các biến kinh tế, xã hội và thái độ của đáp viên, $p$ là số lượng các biến phi thuộc tính. $Z_{k}$ là các biến thuộc tính của cải thảo "nhã̃n hiệu sinh thái". $S_{p}$ là các đặc điểm kinh tế, xã hội, và nhận thức của đáp viên (phi thuộc tính).

Hệ số $\beta$ có thể âm hoặc dương, khác nhau cho mỗi đặc tính sản phẩm và được "định giá" theo sở thích chủ quan của mỗi cá nhân. Hệ số $\beta$ khác nhau giữa các nhóm cá nhân trong một tổng thể nhưng giống nhau cho các cá nhân trong cùng nhóm. Mặc dù có nhiều cách để loại bỏ sự sai phạm không thích đáng từ các lựa chọn và cải thiện mức độ phù hợp của mô hình, mô hình MNL được sử dụng trong nghiên cứu này với hi vọng làm giảm sai sót và mang lại kết quả chính xác nhất cho phương pháp mô hình hóa hành vi lựa chọn này.

Giá ẩn của các thuộc tính được tính toán và sử dụng để thể hiện giá trị của các lựa chọn hay thuộc tính với giả định là các yếu tố khác không đồi (Ceteris paribus). Giá ẩn này chính là mức sã̃n lòng chi trả biên (MWTP) của đáp viên cho sự gia tăng thuộc tính quan tâm với điều kiện các yếu tố khác không đổi (Do \& Bennett, 2009; Khai \& Yabe,
2015). Giá ẩn của mỗi thuộc tính với điều kiện hàm hữu dụng tuyến tính được xác định bằng công thức sau:

$$
G i a ́ \text { ẩn }=M W T P=-\left(\frac{\beta_{\text {thuộc tính }}}{\beta_{\text {giá }}}\right)
$$

Trong đó, $\beta$ là tham số được ước tính trong mô hình MNL dưới dạng phương trình tuyến tính (4).

\subsection{Thiết kế bản câu hỏi và khảo sát số liệu}

Bài viết với kịch bản là giả định Bộ Nông nghiệp và Phát triển nông thôn phối hợp với một bên thứ 3 được nhà nước công nhận - chịu trách nhiệm cung cấp nhãn hiệu "Thực phẩm xanh - Green Food" cho cải thảo, được gọi là cải thảo nhãn hiệu sinh thái, để giải quyết các vấn đề tiêu cực trong an toàn vệ sinh thực phẩm và môi trường. Hình thức canh tác và quy trình sản xuất sẽ mang lại những lợi ích thiết thực cho sức khỏe người tiêu dùng và môi trường.

Bước quan trọng nhất trong việc thiết kế bản câu hỏi thử nghiệm lựa chọn là xác định các thuộc tính tốt và mức độ phù hợp (Khai \& Yabe, 2014). Các đặc tính này phải trả lời được câu hỏi nghiên cứu, sát thực tế, và có thể hiểu được. Sau khi tham khảo ý kiến của chuyên gia và một người tiêu dùng đại diện, bài viết đưa ra bốn thuộc tính của "Cải thảo nhãn hiệu sinh thái” với các mức độ được trình bày ở Bảng 1 và được diễn giải cụ thể như sau:

- Thuộc tính nhãn hiệu cải thảo với bốn mức độ: (1) "Cải thảo thông thường" là loại cải không rõ nguồn gốc xuất xứ, trồng bán mà không qua kiểm định, cấp phép; (2) "Cải thảo an toàn" là cải thảo được trồng bởi các cơ sở có giấy chứng nhận đủ điều kiện sản xuất an toàn, các yêu cầu về chất lượng: Đất, nước tưới, dư lượng thuốc bảo vệ thực vật và vi sinh vật phải nằm trong ngưỡng an toàn; (3) "Cải thảo nhãn hiệu xanh" là cải thảo được dán nhãn “Thực phẩm xanh - Green Food", tuân thủ các điều kiện cơ bản như RAT, đồng thời sản xuất theo một quy trình nghiêm ngặt và đòi hỏi truy xuất nguồn gốc; (4) "Cải thảo hữu cơ" là loại cải theo tiêu chuẩn hữu cơ tuân thủ 3 điều kiện về: đất trồng, sản xuất và đóng gói, hoàn toàn không sử dụng chất hóa học trong suốt vòng đời của sản phẩm; ngoài ra phải đảm bảo điều kiện lao động cho công nhân.

- Thuộc tính độ tươi của cải thảo: Được tính theo số ngày thu hoạch của cải thảo với 3 mức độ: (1) Mới thu hoạch, (2) Thu hoạch trước đó 01 ngày, (3) Thu hoạch trước đó 02 ngày.

- Thuộc tính truy xuất nguồn gốc là khả năng theo dõi, nhận diện được một đơn vị sản phẩm qua từng công đoạn của quá trình sản xuất, chế biến, 
phân phối. Thuộc tính này gồm 2 lựa chọn có và không.

- Thuộc tính mức giá của cải thảo: Tùy theo mức độ an toàn và thân thiện với môi trường, mức giá của cải thảo có năm mức độ: 24.000 đồng/kg, 28.000 đồng $/ \mathrm{kg}, 32.000$ đồng $/ \mathrm{kg}, 36.000$ đồng $/ \mathrm{kg}$ và 40.000 đồng/kg.

\section{Bảng 1: Mô tả thuộc tính và các mức độ của thuộc tính}

\begin{tabular}{|c|c|c|}
\hline THUỘC TÍNH & MỐTẢ & MỨC Độ \\
\hline $\begin{array}{l}\text { Nhãn hiệu cải thảo } \\
\text { (Safe, Green, } \\
\text { Organic) }\end{array}$ & $\begin{array}{l}\text { Safe là nhãn hiệu "Cải thảo an } \\
\text { toàn". } \\
\text { Green là nhãn hiệu "Cải thảo } \\
\text { nhãn hiệu xanh". } \\
\text { Organic là nhãn hiệu "Cải thảo } \\
\text { hữu cơ". }\end{array}$ & $\begin{array}{l}\text { Cải thảo an toàn (mã hóa thuộc tính với } 1 \text { là } \\
\text { đáp viên lựa chọn và ngược lại là } 0 \text { ). } \\
\text { Cải thảo nhãn hiệu xanh (mã hóa thuộc tính với } \\
1 \text { là đáp viên lựa chọn và ngược lại là } 0 \text { ). } \\
\text { Cải thảo hữu cơ (mã hóa thuộc tính với } 1 \text { là đáp } \\
\text { viên lựa chọn và ngược lại là } 0 \text { ). }\end{array}$ \\
\hline \multirow{2}{*}{$\begin{array}{l}\text { Độ tươi cải thảo } \\
\text { (Oneday, Twodays) }\end{array}$} & $\begin{array}{l}\text { Oneday là độ tươi của cải thảo } \\
\text { thu hoạch trước } 1 \text { ngày. }\end{array}$ & $\begin{array}{l}\text { Thu hoạch trước } 1 \text { ngày (mã hóa thuộc tính nếu } \\
\text { đáp viên lựa chọn là } 1 \text {, ngược lại là } 0 \text { ). }\end{array}$ \\
\hline & $\begin{array}{l}\text { Twodays là độ tươi của cải thảo } \\
\text { thu hoạch trước } 2 \text { ngày. }\end{array}$ & $\begin{array}{l}\text { Thu hoạch trước } 2 \text { ngày (mã hóa thuộc tính } \\
\text { nếu đáp viên lựa chọn là } 1, \text { ngược lại là } 0 \text { ). }\end{array}$ \\
\hline $\begin{array}{l}\text { Truy xuất nguồn } \\
\text { gốc (Traceable) }\end{array}$ & $\begin{array}{l}\text { Truy xuất nguồn gốc của sản } \\
\text { phẩm mà đáp viên sẵn lòng chi } \\
\text { trả. }\end{array}$ & $\begin{array}{l}\text { Có nguồn gốc và không nguồn gốc (mã hóa } \\
\text { thuộc tính nếu đáp viên chọn cải thảo có truy } \\
\text { xuất nguồn gốc là } 1 \text {, ngược lại là } 0 \text { ). }\end{array}$ \\
\hline Giá (Price) & $\begin{array}{l}\text { Mức giá của "Cải thảo nhãn } \\
\text { hiệu sinh thái" ( } \mathrm{VNĐ/kg),} \mathrm{có} 5 \\
\text { mức giá. }\end{array}$ & $\begin{array}{l}24.000 \text { đồng, } 28.000 \text { đồng, } 32.000 \text { đồng, } \\
36.000 \text { đồng, } 40.000 \text { đồng. }\end{array}$ \\
\hline
\end{tabular}

Để kiểm tra lại sự phù hợp, rõ ràng và chính xác của các thuộc tính và mức độ, 25 người dân đã được phỏng vấn thử. Việc phỏng vấn thử này cũng giúp loại bỏ sai sót trong quá trình phỏng vấn và hoàn thiện bản câu hỏi, sau đó tiến hành phỏng vấn chính thức 125 người dân tại các khu vực đô thị của thành phố Cần Thơ theo phương pháp chọn mẫu thuận tiện. Theo Louviere et al. (2000), kỹ thuật thiết kế thử nghiệm được áp dụng để tạo ra 25 kết hợp trực giao (orthogonal combinations) và chia thành năm phiên bản câu hỏi khác nhau, mỗi phiên bản bao gồm năm bộ lựa chọn. Trong phần $\mathrm{CE}$, đáp viên trả lời năm sự lựa chọn cải thảo loại $\mathrm{A}$, cải thảo loại $\mathrm{B}$ và cải thảo thông thường. Tùy theo từng loại cải thảo đáp ứng được một hay một vài thuộc tính trên, và mức giá cũng phụ thuộc vào các thuộc tính. Người tiêu dùng sẽ lựa chọn mua cải thảo loại $\mathrm{A}$ và $\mathrm{B}$ sản phẩm thân thiện với môi trường hoặc sẽ mua loại cải thảo thông thường nếu không mua loại $\mathrm{A}$ và $\mathrm{B}$, tùy vào sự lựa chọn và thu nhập của người tiêu dùng, nếu đáp viên không lựa chọn hai lựa chọn $(\mathrm{A}, \mathrm{B})$, họ vẫn lựa chọn loại cải thảo thông thường thì vấn đề về an toàn thực phẩm, bảo vệ sức khỏe, bảo vệ môi trường vẫn không được cải thiện và lợi ích của họ và cộng đồng cũng không được tăng lên. Việc lựa chọn trên hoàn toàn dựa vào mức sẵn lòng chi trả của người tiêu dùng, họ có thể lựa chọn một trong ba loại sản phẩm đã được đề ra.

\section{Bảng 2: Ví dụ về một bộ lựa chọn của mô hình CE}

\begin{tabular}{|c|c|c|c|}
\hline $\begin{array}{l}\text { Những yếu tố sau sẽ thay } \\
\text { đổi tùy theo mức độ quản } \\
\text { lý khác nhau }\end{array}$ & Cải thảo $\mathrm{A}$ & Cải thảo $B$ & $\begin{array}{l}\text { Cải thảo thông } \\
\text { thường }\end{array}$ \\
\hline Nhãn hiệu cải thảo & Cải thảo nhãn hiệu xanh & Cải thảo hữu cơ & Tôi không chọn cả \\
\hline Độ tươi của cải thảo & Thu hoạch trước đó 01 ngày & Thu hoạch trước đó 02 ngày & 2 loại cải thảo $\mathrm{A}$ \\
\hline Truy xuất nguồn gốc & Có & Không & $\begin{array}{l}\text { hoặc B. Tôi chỉ } \\
\text { muốn mua loại cải }\end{array}$ \\
\hline Giá & 36.000 đồng $/ \mathrm{kg}$ & 40.000 đồng $/ \mathrm{kg}$ & $\begin{array}{l}\text { thảo thông thường } \\
\text { với giá } 20.000 \\
\text { đồng/kg }\end{array}$ \\
\hline $\begin{array}{l}\text { Tôi sẽ chọn: (Chỉ chọn } 1 \\
\text { tùy chọn duy nhất) }\end{array}$ & $\square$ & $\square$ & $\square$ \\
\hline
\end{tabular}


Bảng 2 thể hiện mô hình mẫu của sự lựa chọn. Mô hình có 3 loại cải thảo $A$, cải thảo $B$ và cải thảo thông thường. Cải thảo loại $\mathrm{A}$ mang nhãn hiệu xanh, có độ tươi thu hoạch trước 1 ngày, có nguồn gốc và giá là 36.000 đồng/kg. Cải thảo loại $\mathrm{B}$ mang nhãn hiệu hữu cơ, có độ tươi thu hoạch trước 2 ngày, không có nguồn gốc xuất xứ và giá bán là 40.000 đồng $/ \mathrm{kg}$. Cuối cùng là cải thảo thông thường giá chỉ 20.000 đồng $/ \mathrm{kg}$. Tuy nhiên, mỗi thuộc tính của từng loại cải thảo sẽ có mức độ khác nhau, được thay đồi ngẫu nhiên ở các lựa chọn và phiên bản của bản câu hỏi. Đáp viên có thể lựa chọn $\mathrm{A}$ hoặc $\mathrm{B}$ tùy theo sở thích và cảm nhận của họ.

Phương pháp CE được sử dụng để xác định mối quan hệ giữa các dữ liệu thí nghiệm lựa chọn, sau đó áp dụng mô hình MNL để ước lượng mức sẵn lòng chi trả (WTP) của người tiêu dùng cho từng thuộc tính của cải thảo đề xuất bằng phần mềm Nlogit 5.0. Hàm thỏa dụng của người tiêu dùng được tạo ra bởi một trong ba sự lựa chọn như đã trình bày ở bản câu hỏi. Gọi $V_{\mathrm{i}}$ là độ thỏa dụng của người tiêu dùng nhận được khi lựa chọn $j$ và $A S C$ là hằng số của phương trình độ thỏa dụng cho từng lựa chọn cụ thể, nó còn chứa đựng giá trị trung bình, sai số và các yếu tố không thể quan sát được. Phương trình độ thỏa dụng tuyến tính gồm các biến thuộc tính của người tiêu dùng trong nghiên cứu này có dạng như sau:

\section{Lựa chọn 1:}

$V_{1}=$ ASC $+\beta_{1}$ Price $+\beta_{2}$ Safe $+\beta_{3}$ Green + $\beta_{4}$ Organic $+\beta_{5}$ Oneday $+\beta_{6}$ Twodays + $\beta_{7}$ Traceable

\section{Lựa chọn 2:}

$V_{2}=$ ASC $+\beta_{1}$ Price $+\beta_{2}$ Safe $+\beta_{3}$ Green + $\beta_{4}$ Organic $+\beta_{5}$ Oneday $+\beta_{6}$ Twodays + $\beta_{7}$ Traceable

\section{Lụa chọn 3:}

$$
\begin{aligned}
& V_{3}=\beta_{1} \text { Price }+\beta_{2} \text { Safe }+\beta_{3} \text { Green }+ \\
& \beta_{4} \text { Organic }+\beta_{5} \text { Oneday }+\beta_{6} \text { Twodays }+ \\
& \beta_{7} \text { Traceable }
\end{aligned}
$$

\section{KẾT QUẢ VÀ THẢO LUẬN}

Bảng 3 trình bày đặc điểm kinh tế xã hội của đáp viên. Kết quả cho thấy độ tuổi trung bình của đáp viên khoảng 35 tuổi, với độ tuổi thấp nhất khoảng 20 tuổi và cao nhất là 64 tuổi. Khoảng $52 \%$ đáp viên có độ tuổi lớn hơn hoặc bằng $30,48 \%$ người có độ tuổi nhỏ hơn 30 tuổi chiếm $48 \%$, và khoảng $44,8 \%$ người trong độ tuổi lao động từ 30 đến 55 tuổi. Như vậy, các đáp viên có tuổi nhỏ nhất là 20 tuổi, đều đã trưởng thành, có thể là chủ hộ hay trụ cột của gia đình, và là người có thu nhập chính của gia đình và có thể quyết định chọn mua.

\section{Bảng 3: Đặc điểm về nhân khẩu học và kinh tế xã hội của đáp viên}

\begin{tabular}{lrr}
\hline Đặc điểm & Giá trị trung bình & Độ lệch chuẩn \\
\hline Tỷ lệ đáp viên là giới tính nam (\%) & 23 & 0,42 \\
Tuồi của người trả lời (năm) & 34,74 & 11,99 \\
Số năm đi học của đáp viên (năm) & 14,68 & 2,62 \\
Tổng số người trong gia đình (người) & 3,78 & 1,42 \\
Thu nhập trung bình hàng tháng của đáp viên (triệu đồng) & 8,94 & 5,74 \\
\hline
\end{tabular}

Với tỷ lệ đáp viên là nam chiếm chỉ khoảng $23 \%$, còn lại là nữ chiếm $77 \%$, chứng tỏ sự chênh lệch số lượng giữa đáp viên nam và nữ lớn. Tuy nhiên, điều này có thể được giải thích là do người phụ nữ sẽ là người đảm nhận công việc nhà, là người trực tiếp đi chợ lựa chọn mua đồ mồi ngày để chế biến cho gia đình ăn nên họ sẽ biết rõ và cân nhắc lựa chọn những sản phẩm an toàn tươi ngon để tốt cho sức khỏe của gia đình. Vì vậy, sự chênh lệch về tỷ lệ giữa nam và nữ có thể được chấp nhận trong nghiên cứu này.

Đáp viên có số năm đi học trung bình khá cao, khoảng 15 năm đi học chiếm đến $73 \%$ đáp viên có trình độ cao đẳng đại học trở lên nhiều nhất do địa bàn nghiên cứu là thành phố trung tâm của Đồng bằng sông Cửu Long. Quy mô hộ gia đình của đáp viên khoảng 4 người với tỷ lệ khoảng $58,4 \%$ gia đình có $3-4$ thành viên, đây là gia đình hai thế hệ gồm cha mẹ và con cái. Thu nhập trung bình hàng tháng của các đáp viên khoảng 8,94 triệu đồng, trong đó đa phần đáp viên có mức thu nhập trung bình khoảng 6.000.000 đồng - 9.000.000 đồng/tháng, chiếm $41,6 \%$; kế đến là mức thu nhập trung bình khoảng 3.000.000 đồng -6.000 .000 đồng/tháng, chiếm khoảng 22,4\%.

Bảng 4 trình bày kết quả ước lượng của mô hình logit đa thức (MNL) đối với các thuộc tính của sự lựa chọn cải thảo sử dụng các công thức (6), (7), và (8). Kết quả cho thấy rằng các thuộc tính đều là những yếu tố quan trọng để khả năng chi trả của người tiêu dùng cho cải thảo được đề xuất. Hệ số $A S C$ của mô hình có ý nghĩa thống kê ở mức $1 \%$, điều này cho thấy khi người tiêu dùng lựa chọn sử dụng cải thảo có đặc tính của nhãn hiệu sinh thái (cải thảo $\mathrm{A}$ và cải thảo $\mathrm{B}$ ) thì thỏa dụng của họ cao hơn 
so với khi sử dụng cải thảo thông thường (giả sử người tiêu dùng đang sử dụng). Khi giá càng tăng lên thì độ thỏa dụng của người tiêu dùng bị giảm đi, vì vậy hệ số của biến giá (Price) mang dấu âm với mức ý nghĩa $1 \%$.

Bảng 4. Kết quả ước lượng của mô hình logit đa thức đối với sự lựa chọn cải thảo

Đơn vị tính: Đồng/kg

\begin{tabular}{lrr}
\hline Biến & Hệ số & Sai số chuẩn \\
\hline ASC & $0,67883^{* * *}$ & 0,24216 \\
Price & $-0,09638^{* * *}$ & 0,01408 \\
Safe & $0,95658^{* * *}$ & 0,16839 \\
Green & $1,12066^{* * *}$ & 0,20839 \\
Organic & $1,48826^{* * *}$ & 0,21102 \\
Oneday & 0,11612 & 0,15158 \\
Twodays & $-0,24673$ & 0,16604 \\
Traceable & $1,39245^{* * *}$ & 0,12414 \\
Log-likelihood & $-490,61322$ & \\
$\rho^{2}$ & 0,2061 & \\
Quan sát & 625 & \\
\hline
\end{tabular}

Ghi chú: ${ }^{* * *},{ }^{* *}$, và * turong úng với múc ý nghĩa 1\%, 5\%, và $10 \%$.

Các hệ số của các thuộc tính nhãn hiệu như "Cải thảo an toàn" (Safe), "Cải thảo nhãn hiệu xanh" (Green), và "Cải thảo hữu cơ" (Organic) và thuộc tính truy xuất nguồn gốc (Traceable) đều mang dấu dương ở mức ý nghĩa thống kê $1 \%$, chứng tỏ khi tồn tại các thuộc tính này lên thì độ thỏa dụng cũng sẽ cao hơn. Tuy nhiên, người tiêu dùng ở thành phố Cần Thơ không quan tâm nhiều đến thuộc tính độ tươi của cải thảo nên hệ số của thuộc tính về thu hoạch trước đó 01 ngày (Oneday) và thu hoạch trước đó 02 ngày (Twodays) không có ý nghĩa thống kê.
Giá ngầm định (ẩn) cho mỗi thuộc tính được sử dụng để biểu thị mức sẵn lòng trả cận biên (MWTP) cho một sự thay đổi của một thuộc tính. Giá ẩn được ước tính bằng cách sử dụng tỷ lệ giữa các tham số của biến thuộc tính và tham số của biến Price được thể hiện ở công thức (5).

Bảng 5 cho thấy giá ẩn cho mỗi thuộc tính của cải thảo. Kết quả cho thấy người dân ở thành phố Cần Thơ sẵn lòng trả thêm khoảng 10.000 đồng $/ \mathrm{kg}$ cho "Cải thảo an toàn" (Safe), chi trả thêm khoảng 12.000 đồng $/ \mathrm{kg}$ cho cải thảo với nhãn hiệu "Cải thảo xanh" (Green) và 15.000 đồng cho nhãn hiệu "Cải thảo hữu cơ" (Organic). Mức sã̃n lòng chi trả cho các nhãn hiệu của rau cải thảo tăng dần theo mức độ tăng của nhãn hiệu. Kết quả nghiên cứu này tương tự với một số nghiên cứu trước đây. Cụ thể, nghiên cứu của Wang (2018) về sự sẵn lòng trả của người tiêu dùng cho thịt heo với các nhãn hiệu chứng nhận cho thấy rằng người tiêu dùng sẵn sàng trả cao nhất cho thuộc tính chứng nhận "Organic Food", theo sau đó là thuộc tính chứng nhận "Green Food" và cuối cùng là "Safe Food". Nghiên cứu của Yu (2014) về sự sẵn lòng chi trả cho thực phẩm xanh ở Trung Quốc cũng cho thấy rằng người tiêu dùng sẵn lòng trả cao hơn $47 \%$ cho "Green vegetable" và $40 \%$ cho "Green meat". Tương tự như vậy, nghiên cứu của Suanmali (2020) cũng cho thấy "Organic Fruits and vegetable" cũng được người tiêu dùng sẵn sàng trả cao hơn $60 \%$ so với thực phẩm thông thường. Biến thuộc tính truy xuất nguồn gốc (Traceable) là biến khá quan trọng, vì vậy mức sẵn lòng chi trả của người tiêu dùng tương đối cao, cụ thể là người tiêu dùng sẽ sẵn sàng chi thêm 14.000 đồng $/ \mathrm{kg}$ cho rau cải thảo có nguồn gốc rõ ràng, có thể nói đây là vấn đề được người tiêu dùng quan tâm đầu tiên khi lựa chọn mua rau.

Bảng 5. Giá ẩn hay mức sẵn lòng chi trả biên cho các thuộc tính của cải thảo

Đơn vị tính: Đồng/kg

\begin{tabular}{lrrr}
\hline \multirow{2}{*}{ Thuộc tính } & \multirow{2}{*}{ Trung bình } & \multicolumn{2}{c}{ Khoảng tin cậy 95\% } \\
\cline { 3 - 4 } & & Cận trên & Cận dưới \\
\hline Safe & $9.925,09^{* * *}$ & $5.821,83$ & $14.028,35$ \\
Green & $11.627,6^{* * *}$ & $6.160,9$ & $17.094,3$ \\
Organic & $15.441,6^{* * *}$ & $9.898,9$ & $20.984,3$ \\
Oneday & 1204.86 & -1893.52 & 4303.24 \\
Twodays & -2559.95 & -6245.44 & 1125.54 \\
Traceable & $14.447,5^{* * *}$ & $9.935,7$ & $18.959,4$ \\
\hline
\end{tabular}

Ghi chú: ***, **, và * tưong úng với múc ý nghĩa 1\%, 5\%, và $10 \%$.

Từ đó cho thấy điều mà người tiêu dùng quan tâm nhất chính là sức khỏe của bản thân và chính gia đình của họ. Người tiêu dùng luôn lựa chọn những sản phẩm có nguồn gốc rõ ràng, chính vì vậy thuộc tính nguồn gốc được người tiêu dùng chi trả rất cao, và nhãn hiệu "Cải thảo hữu cơ" nói chung đều có nguồn gốc xuất xứ rõ ràng, là nhãn hiệu an toàn tốt 
nhất nên đây là nhãn hiệu người tiêu dùng chi trả cao nhất trong số 3 nhãn hiệu trên.

\section{KẾT LUẬN VÀ KIẾN NGH!}

Bài viết phân tích thị hiếu thông qua ước tính mức sẵn lòng chi trả của người dân ở thành phố Cần Thơ cho các thuộc tính của cải thảo được đề xuất với nhãn hiệu xanh bằng phương pháp thí nghiệm lựa chọn $(\mathrm{CE})$. Kết quả cho thấy rằng đáp viên có mức sẵn lòng trả thêm cao đối với cải thảo có nhãn hiệu "Cải thảo hữu cơ" (khoảng 15.000 đồng $/ \mathrm{kg}$ ), kế tiếp là cải thảo có thông tin truy xuất nguồn gốc rõ ràng (khoảng 14.000 đồng $/ \mathrm{kg}$ ). Các thuộc tính còn lại có mức trả thêm thấp hơn, cụ thể là người tiêu dùng sẽ trả thêm khoảng 10.000 đồng $/ \mathrm{kg}$ cho "Cải thảo an toàn" và khoảng 12.000 đồng $/ \mathrm{kg}$ cho "Cải thảo xanh". Điều này cho thấy người tiêu dùng quan tâm nhất chính là sức khỏe của bản thân và chính gia đình của họ.

Với mong muốn mang lại những sản phẩm an toàn, xanh, sạch cho người tiêu dùng, nâng cao kiến thức về an toàn thực phẩm của người dân Việt Nam nói chung, người dân ở thành phố Cần Thơ nói riêng và bảo vệ môi trường cũng như hệ sinh thái, các biện pháp được đề xuất như sau:

- Trước hết là người dân cần trang bị kiến thức về an toàn thực phẩm tốt, hiểu biết về rau xanh đạt tiêu chuẩn rau an toàn; tổ chức các buổi tuyên truyền về an toàn thực phẩm tại địa phương để bố sung kiến thức mới cho người dân kịp thời nắm bắt, thực hiện tháng hành động an toàn thực phẩm, thường xuyên kiểm tra và xử lý các cơ sở kinh doanh theo đúng quy định đã đề ra; ngoài ra tuyên truyền thông tin qua loa phát thanh, bảng hiệu, băng rôn (bandroll), truyền hình để cung cấp thêm thông tin cho những người bận rộn không có thời gian xem tin tức.

- Phần lớn người dân còn xa lạ với khái niệm thực phẩm xanh, vì vậy nhà nước cần đẩy mạnh hỗ trợ tạo điều kiện cho nhà nông canh tác cải thảo "nhãn hiệu sinh thái" trồng nhiều hơn; giới thiệu quảng cáo thông tin về thực phẩm xanh, khuyến khích người tiêu dùng nên mua sử dụng thử, bên cạnh thường xuyên tổ chức công tác kiểm tra an toàn thực phẩm tại nơi trồng trọt chế biến và bảo quản, áp dụng tiến bộ khoa học kĩ thuật, trồng kết hợp sử dụng máy móc công nghệ cao, giúp tăng năng suất và hạn chế sử dụng lao động nhiều.

- Bộ Nông nghiệp và Phát triển nông thôn cần phối hợp với tổ chức gọi là bên thứ 3 để cấp giấy chứng nhận nhãn mác về nhãn hiệu sinh thái từ khâu trồng trọt đến chế biến phải đạt đúng tiêu chuẩn đã đề ra; từ đó khuyến khích các công ty doanh nghiệp cơ sở sản xuất nhỏ trồng theo tiêu chuẩn đó, giúp tăng sự hiện diện của sản phẩm nhãn sinh thái trong các cửa hàng để phục vụ nhu cầu con người, giá thành phù hợp với thu nhập của người dân, bày bán sản phẩm cải thảo nhãn sinh thái tại các cửa hàng ở từng khu vực giúp cho người tiêu dùng mua sắm thuận tiện; không dừng lại ở cải thảo "nhãn hiệu sinh thái - Eco-label" mà phải không ngừng nâng cao sản xuất ra nhiều loại sản phẩm an toàn khác với chất lượng ngày càng tốt hơn, vì một môi trường xanh sạch không bị ô nhiễm và bảo vệ sức khỏe của con người.

\section{LÒ̀I CẢM TẠ}

Đề tài này được tài trợ bởi Dự án Nâng cấp Trường Đại học Cần Thơ VN14-P6 bằng nguồn vốn vay ODA từ chính phủ Nhật Bản.

\section{TÀI LIỆU THAM KHẢO}

Adamowicz, W., Boxall, P., Williams, M., \& Louviere, J. (1998). Stated preference approaches for measuring passive use values: choice experiments and contingent valuation. American Journal of Agricultural Economics, 80(1), 64-75. https://doi.org/10.2307/3180269

Bennett, J., \& Adamowicz, V. (2001). The Choice Modelling Approach to Environmental Valuation. Jeff Bennett and Russell Blamey (Eds.). New horizons in environmental economics, 37-69.

Do, T. N., \& Bennett, J. (2009). Estimating wetland biodiversity values: a choice modelling application in Vietnam's Mekong River Delta. Environment and Development Economics, 14(2), 163-186. https://doi.org/10.1017/S1355770X08004841

Hanley, N., Mourato, S. and Wright, R., (2001). Choice modelling approaches: a superior alternative for environmental valuation?, Journal of Economic Surveys, 15(3), 453- 462. https://doi.org/10.1111/1467-6419.00145

Khai, H. V. (2017). An Evaluation of Consumer Willingness to Pay for Organic Vegetables in the Vietnamese Mekong Delta. Justin A. Daniels (Ed.), Advances in Environmental Research.

Khai, H. V., \& Yabe, M. (2014). Choice modeling: assessing the non-market environmental values of the biodiversity conservation of swamp forest in Vietnam. International Journal of Energy and Environmental Engineering, 5(1), 1-8. https://doi.org/10.1007/s40095-014-0077-5 
Khai, H. V., \& Yabe, M. (2015). Consumer preferences for agricultural products considering the value of biodiversity conservation in the Mekong Delta, Vietnam. Journal for nature conservation, 25, 62-71. https://doi.org/10.1016/j.jnc.2015.02.004

Khai, H. V., Duyen, T. T. T., \& Xuan, H. T. D. (2020). Willingness to Pay for Certified Safer Pork and Implications for Sustainable Consumption: A Case Study of the Vietnamese Mekong Delta. Luke Amadi and Fidelis Allen (Eds.), Global Food Politics and Approaches to Sustainable Consumption: Emerging Research and Opportunities, 142-156. https://doi.org/10.4018/978-1-7998-01252.ch007

Lancaster, K.J. (1966). A new approach to consumer theory. The Journal of Political Economy, 74(2), 132-157. https://doi.org/10.1086/259131

Louviere, J., Hensher, D., Swait, J., \& Adamowicz, W. (2000). Stated Choice Methods: Analysis and Applications. Cambridge: Cambridge University Press. https://doi.org/10.1017/CBO9780511753831

Nguyễn Văn Thuận \& Võ Thành Danh (2011). Phân tích các yếu tố ảnh hưởng đến hành vi tiêu dùng rau an toàn tại Thành Phố Cần Thơ. Tạp chi Khoc học Trưòng Đại học Cần Tho, 17b, 113-119.
Phong Nguyễn. (2020). Trên 100.000 tấn thuốc bảo vệ thực vật nhập khẩu mối năm: Có kiểm soát được chất luợng?, truy cập ngày 05/06/2021 tại https://laodong.vn/xa-hoi/tren-100000-tanthuoc-bao-ve-thuc-vat-nhap-khau-moi-nam-cokiem-soat-duoc-chat-luong-852005.1do

Sở Nông nghiệp và Phát triển nông thôn thành phố Hồ Chí Minh (2018). Kết quả thực hiện chuoong trình phát triển rau an toàn năm 2018, truy cập ngày $01 / 11 / 2020$ tại http://www.sonongnghiep.hochiminhcity.gov.vn /tintuc/Lists/Posts/ViewPost.aspx ?ID=3270

Suanmali, S. (2020). Determinants of A Customer's Willingness to Pay (WTP) for Organic Fruits and Vegetables: An Empirical Study in the Bangkok Metropolitan Area. International Journal of Trade, Economics and Finance, 11(4), 71-76.

https://doi.org/10.18178/ijtef.2020.11.4.669

Wang, J., Jiaye Ge, J. \& Ma, Y. (2018). Urban Chinese Consumers' Willingness to Pay for Pork with Certified Labels: A Discrete Choice Experiment. Sustainability, 10(3), 603. https://doi.org/10.3390/su10030603

Yu, X., Gao, Z., \& Zeng, Y. (2014). Willingness to pay for the "Green Food" in China. Food policy, 45, 80-87. https://doi.org/10.1016/j.foodpol.2014.01.003 